\title{
Lucie VEYRETOUT, L'admission des femmes aux fonctions cultuelles. Une question de droit(s)
}

Strasbourg, Presses universitaires de Strasbourg, 2016, 200 p.

\section{Gwendoline Malogne-Fer}

\section{CpenEdition}

Journals

Édition électronique

URL : https://journals.openedition.org/assr/45266

DOI : $10.4000 /$ assr.45266

ISSN : 1777-5825

Éditeur

Éditions de l'EHESS

Édition imprimée

Date de publication : 1 décembre 2018

Pagination : 384-385

ISSN : 0335-5985

\section{Référence électronique}

Gwendoline Malogne-Fer, « Lucie veyretout, L'admission des femmes aux fonctions cultuelles. Une question de droit(s) », Archives de sciences sociales des religions [En ligne], 184 | octobre-décembre 2018, mis en ligne le 01 décembre 2018, consulté le 11 janvier 2022. URL : http:// journals.openedition.org/assr/45266 ; DOI : https://doi.org/10.4000/assr.45266

Ce document a été généré automatiquement le 11 janvier 2022.

(c) Archives de sciences sociales des religions 


\title{
Lucie VEYRETOUT, L'admission des femmes aux fonctions cultuelles. Une question de droit(s)
}

Strasbourg, Presses universitaires de Strasbourg, 2016, 200 p.

\author{
Gwendoline Malogne-Fer
}

\section{RÉFÉRENCE}

Lucie VeYRetout, L'admission des femmes aux fonctions cultuelles. Une question de droit(s), Strasbourg, Presses universitaires de Strasbourg, 2016, 200 p.

1 Ce livre est issu d'une thèse de doctorat en droit des religions, soutenue en 2013 à l'Université de Strasbourg, intitulée «L'application des droits de l'être humain au sein des groupements religieux : recherches relatives à la question de la discrimination des femmes dans l'accès aux fonctions cultuelles». Bien que le titre du livre ne le mentionne pas explicitement, l'auteure analyse la non-admission des femmes aux fonctions cultuelles, principalement au sein du catholicisme, du judaïsme et de l'islam, et les arguments juridiques mobilisés pour refuser l'accès des femmes aux fonctions de prêtre, de rabbin ou d'imam. Elle étudie prioritairement le cas français à l'époque contemporaine en montrant l'influence du droit international et du droit européen sur le droit positif français et en comparant le cas français à celui d'autres pays européens et nord-américains (États-Unis et Canada). L'ouvrage, qui se compose de deux parties et quatre chapitres, place au cœur de la réflexion la tension entre l'égalité des sexes et la liberté religieuse. La première partie, "La liberté de religion préservée dans la lutte contre les discriminations ", étudie, d'une part, l'élaboration du principe juridique de l'égalité des sexes et de la lutte contre les discriminations et, d'autre part, la nonapplication de l'égalité des sexes aux fonctions cultuelles au nom du respect du principe de liberté religieuse, principe qui permet aux communautés religieuses de s'organiser comme elles le souhaitent. Dans la seconde partie, «La portée de l'égalité 
des sexes sur les normes religieuses", l'auteure montre l'extension de ce principe d'égalité des sexes - notamment dans le domaine de la vie privée, conjugale et familiale - et la limitation (relative) de la liberté religieuse qui en découle. Enfin, dans le dernier chapitre sont analysés les cas d'accession des femmes aux fonctions culturelles notamment dans les églises d'État des pays nordiques et en Angleterre.

2 L'intérêt de cet ouvrage est d'aborder la thématique de l'accès des femmes aux fonctions cultuelles sous un angle juridique et de montrer les nombreuses similitudes qui peuvent exister entre différents groupes religieux d'un même pays ou de pays différents. Néanmoins cette approche juridique, en présentant l'égalité des sexes comme une évolution inéluctable et irréversible, accorde moins d'importance, à quelques exceptions, aux résistances et stratégies de contournement que ce processus égalitaire - qui est loin d'être linéaire - suscite.

3 L'auteure souligne des tensions grandissantes entre le principe de liberté religieuse (qui implique le principe de non-ingérence des États dans le mode de sélection et de rémunération des ministres du culte) et l'extension du principe d'égalité des sexes. Mais l'analyse des exemples français de limitation de la liberté religieuse mériterait d'être nuancée et complexifiée. En effet, l'interdiction du port du voile à l'école publique (mars 2004) et l'interdiction du port du voile intégral dans l'espace public (octobre 2010) ont fait l'objet d'interprétations divergentes concernant la pertinence de la mobilisation de l'égalité des sexes puisque cette restriction de la liberté religieuse s'exerce exclusivement à l'encontre de femmes musulmanes. La Cour européenne des droits de l'homme, tout en concluant que l'interdiction de porter un voile intégral n'est pas contraire à la Convention européenne des droits de l'homme, ne retient pas le premier argument invoqué par le gouvernement français - le respect de l'égalité entre les hommes et les femmes - mais le principe du "vivre ensemble » et "constate en outre que cette interdiction a un fort impact négatif sur la situation des femmes qui ont fait le choix de porter le voile intégral pour des raisons tenant à leurs convictions et que de nombreux acteurs nationaux et internationaux de la protection des droits fondamentaux considèrent qu'une interdiction générale est disproportionnée " (arrêté de la Grande Chambre de la CEDH du $1^{\text {er }}$ juillet 2011). De surcroît cette limitation de la liberté religieuse concerne exclusivement des individus alors que la non-admission des femmes aux fonctions cultuelles est justifiée par le principe d'autonomie des groupements religieux dans leur dimension collective. La démonstration d'une extension du champ d'application de l'égalité des sexes grâce à une limitation de la liberté religieuse - à l'encontre de femmes musulmanes portant le voile - apparaît par conséquent fragile. En revanche, les développements jurisprudentiels relatifs aux droits du travail et aux droits sociaux des ministres du culte laissent envisager de nouvelles réflexions et obligations des organisations religieuses qui pourraient déboucher, à terme, sur une remise en cause de l'inapplicabilité du principe d'égalité des sexes aux groupements religieux, notamment lorsque ces derniers reçoivent des subventions publiques, comme c'est le cas en Belgique.

4 Le dernier chapitre analyse le cas des églises - notamment des églises nationales dans les pays nordiques (Suède, Norvège, Danemark) et l'église établie d'Angleterre - qui autorisent les femmes au pastorat (au sein du protestantisme) et à la prêtrise (dans l'anglicanisme). Les exemples des pays nordiques, comme la Suède, sont intéressants et permettent de faire le lien, au nom d'un "féminisme d'État", entre la politique étatique de promotion de l'égalité des sexes et l'interventionnisme ou le contrôle de ces 
États envers ces églises nationales. Enfin, l'étude de l'accession des femmes aux fonctions cultuelles décidée par les autorités religieuses met davantage en avant des arguments d'ordre théologique ou idéologique. Tout en s'éloignant sensiblement de l'approche juridique et jurisprudentielle adoptée tout au long de l'ouvrage, elle permet de mieux prendre en compte la grande diversité interne à chaque confession ou dénomination, comme le montre par exemple l'analyse des mouvements juifs libéraux et massorti aux États-Unis. L'auteure ne semble pas envisager que des femmes puissent accéder aux fonctions cultuelles en mobilisant le registre de l'exceptionnalité plutôt que celui de l'exemplarité, ce qui aurait pour effet de dissocier l'admission des femmes aux fonctions cultuelles d'une approche militante en faveur de l'égalité des sexes. Pourtant, une des caractéristiques des mouvements féministes religieux est de ne pas mettre systématiquement en avant des arguments "séculiers ", comme l'égalité des sexes, qui risqueraient de porter atteinte à la spécificité de l'organisation religieuse, mais une meilleure conformité aux textes religieux d'où découlerait in fine l'égalité des sexes. 